\title{
REVEALING, ORGANIZING AND ACTIVATING THE LOCAL RESOURCES IN THE FRAMEWORK OF PARTICIPATORY AND CULTURAL TOURISM: THE EXAMPLE OF THESSALY
}

\section{Konstantinos Patsis, Dimitrios Goussios}

University of Thessaly, Volos, Greece
Correspondence:

Konstantinos Patsis

e-mail:

kpatsis@uth.gr

\begin{abstract}
:
The systematic adoption of the conventional mass tourism model by many geographical tourist destinations has undoubtedly contributed to their economic growth. However, it has also caused damage to the natural and social environment due to the high seasonality of the phenomenon and the uncontrolled accumulation of tourist activity. This damage which has contributed to the gradual degradation of the tourism product has led to the diversification of tourism demand and the search for a new tourism product based more on local and cultural values and directly related to the other sectors of economy. The search for the desired restructuring of the tourism product can be integrated into the territorial approach of development, which focuses on the competitiveness and attractiveness of a place through the construction and promotion of its territorial resources. This paper presents a functional framework through the example of Thessaly for the activation of unique tangible and intangible resources as goods and services, which can ensure distinctiveness in the final tourism product offered by a place. The functionality of this framework requires the existence of a central management coordination, flexible supporting infrastructures and initiatives, as well as the planning of innovative participatory and cultural tourist activities.
\end{abstract}

\section{Keywords:}

Territorial development, distinctiveness, unique tangible and intangible resources

\section{INTRODUCTION}

Human nature exploring new places and cultures and seeking interests different from everyday life combined with the internationalization of markets and the complex view of leisure time (Deffner, 2006), the reduction of time and cost travel, the new technologies and other factors of demographic and political changes, have turned tourism planning into a complex procedure. Every possible tourist destination in an effort to adapt to the increasing visitor demands and to be more attractive and competitive against tourism markets usually chooses to invest in the reproduction of generic resources ${ }^{1}$ reducing the cost of the offered goods and services at the expense of the quality of the final tourism

1 Generic resources exist in a place as a raw material but also exist in other places and their price is determined by the market on the basis of supply and demand (Goussios, 2016: p.36). 
product. Efforts to implement several alternative models eventually strengthened the shift from mass to cultural tourism given that huge funds are being invested by governments in order to promote existing and/or create new impressive attractions. The development of cultural tourism which has led to a second generation of tourists was unable to maintain and reproduce such activities because it relied solely on visits. That is to say, tourists were hardly motivated to repeat their trip to a tourist destination they had already visited. Against this tendency to homogenize human search and interest, apparently unable to meet real tourism demand, ways should be sought to enhance the preservation of local specific features and cultural diversity that have been proved to be the only reasons for someone to travel and live authentic experiences that does not easily find in his or her place (Kostakis, 2003). This search led to the assumption that cultural heritage and the uniqueness of a place's resources should be the basis for the offered tourism product, which in order to stand in the international and competitive market of demanding and independent tourists should be based on the authenticity of the tourist experience. One way to achieve this is by encouraging participation and creativity, as well as following the trend towards a possible third generation of tourists given the significant increase in tourism demand in this direction.

\section{NEW TRENDS IN TOURISM ACTIVITY}

\section{Experience-based and creative tourism}

Recently, the introduction of experience (Pine \& Gilmore, 1998) in the tourism sector as a final product of the visitor's participation in authentic tourist activities that can be turned into unique and unforgettable memories has significantly affected the international tourism demand and supply. Real life experiences and memories they create are the ones that motivate people to travel and transform journeys into priceless activities. Today's travelers seek experiences rather than finding satisfying hotel amenities or buying souvenirs or taking the traditional selfie in front of classical attractions (musts) which are spotted in the tourist guides. They also need time to get familiar with a place (slow tourism), to perceive images, sounds, flavors and emotions through the contact with history, culture, geomorphology, gastronomy and folklore, in other words to live like a local, to experience the uniqueness the place can offer. Searching for authentic experiences through participation in tourist activities that are part of the cultural heritage of a place is defined as experience-based tourism, which focuses on a wide range of alternative forms of tourism respecting the environment and local culture.

Creative tourism is directly related to experience-based tourism, which refers to participatory and authentic experiences that allow tourists to develop their creative potential and skills through the contact with local people and their culture (Richards, 2011).The idea of creative tourism has begun spreading in different places of the world depending on the possibilities offered in each case. Many destinations have already developed their own model of creative tourism based on their popular cultural attractions. At organizational level we find the Creative Tourism Network which was established in Barcelona in 2010 and aims at the promotion of tourism destinations worldwide (countries, cities or villages) that can support organized tourism activities. In Paris (Creative Paris), special reception workshops for the tourists were created based on a categorization of the creative tourism products offered with a tendency to spread throughout the country (Creative France). Similar networks can be found in Austria (Creative Tourism Austria), New Zealand (Creative Tourism New Zealand), Taiwan (Creative Life Industry of Taiwan) and New Mexico (Santa Fe Creative Tourism). Furthermore, it is not surprising that according to recent annual rankings of international tourism destinations according to arrivals (UNWTO, 2017) all the countries mentioned above continue to share the first places in the tourist preferences and this is probably due to the diversification of their tourism product.

\section{Participatory tourism, creativity and local development}

\section{"Tell me and I forget. Teach me and I may remember. Involve me and I learn."}

These words by Benjamin Franklin include the importance of participation in any activity that can offer a new interest or even a better unique experience. Particularly in the field of tourism, the concept of participation is broadly applied and directly linked to the notion of creativity since the latter can arise as a result of 
the former. Participatory tourism refers to the consumers (tourists) involvement in making acquaintances and direct contact with local culture activities that often help them develop their real potential and skills. It also refers to the local community and stakeholders active involvement in participatory tourism planning in order to build and activate unique tourist experiences. According to de Bruin and Jelincic (2016) participatory experience tourism can describe better the complex concept of participation because it is presented as an extension of creative tourism and as an umbrella it involves a process of added value in an experience through the active participation of tourists, where the value of all goods and services is co-created or produced through the interaction of consumers and producers. Furthermore, according to Richards (2011: pp. 1238-1239) and depending on the active tourist participation rate, creativity (as activity or as background) forms different types of experiences and products (see Figure 1).

Creativity by definition refers to the production of new ideas or combination of known data for something new giving value to the final result. Linking creativity - as a development tool-to tourism, in the sense of tourists $^{2}$ participating in creating the final product rather than just buying or consuming it, came up as a result of the general picture of cultural tourism given that in many cases it evolved into just another expression of mass tourism (Richards, 2011). Perhaps more attention should be paid to the activation of tourism promotion networks and the creation of travel packages including various local cultural activities, so as to make the tourist destination more attractive and competitive (Kostakis, 2003). One thing is for sure, that searching for ways of combining cultural and participatory tourism is the only approach to restructure the tourism product while their separation may lead to another needless development option that simply breaks apart tourist activity in favor of mass and unorganized tourism.

Figure 1. Gradual development of tourism demand and tourism activity

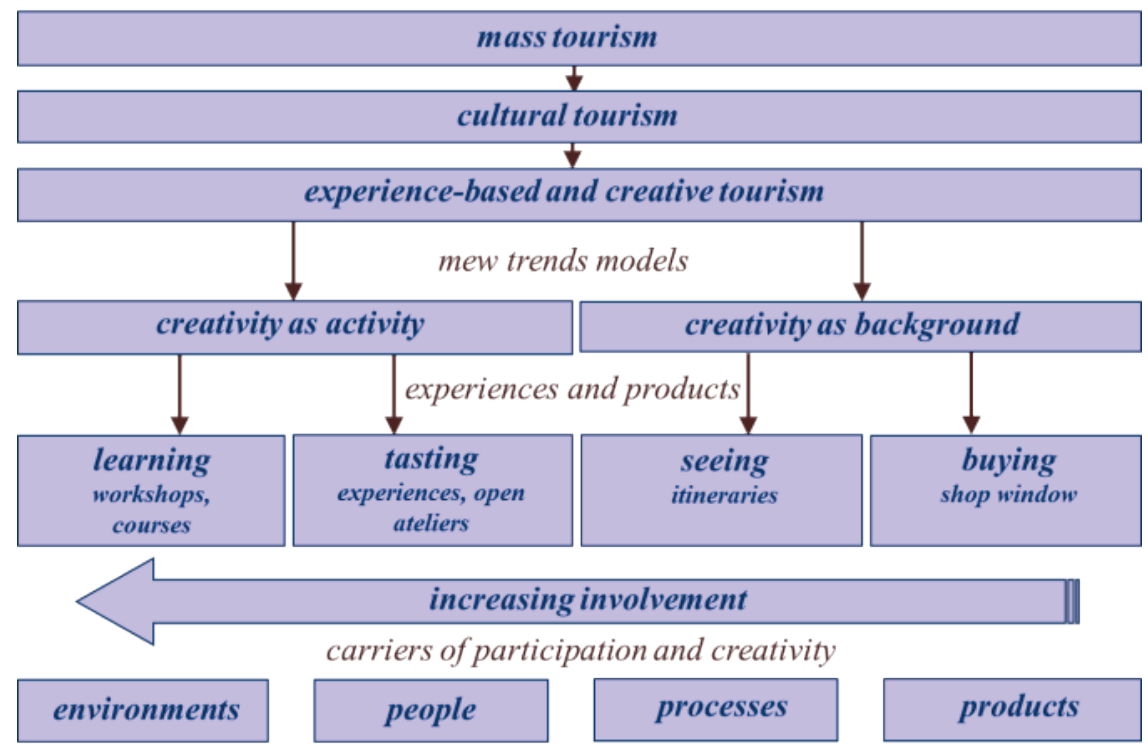

Source: Own illustration, adapted from Richards (2011)

\section{RESULTS AND DISCUSSION}

\section{Implementation framework of methodological approach}

This paper aims to create a functional framework for the activation of tangible and intangible resources of Thessaly ${ }^{3}$ that can lead to the acquisition of unique experiences or/and the revelation of creative actions through the participation of tourists and local community in cultural activities. This framework initially

2 Usually these tourists are called prosumers combining the words producers and consumers.

3 Thessaly is a traditional geographic and modern administrative region of central Greece with approximately 735.000 inhabitants. 
includes identifying, organizing and activating tangible and intangible resources and then creating cultural topics and thematic itineraries. In particular, there are unique experiences or/and creative actions that can be translated into final products and services through a participatory process of tourist activities with the contribution of tourists, enterprises, stakeholders and the local community adding to the distinctiveness of the place. But the most important aspect in this framework is feedback, where emerged products and services will help to improve or create new thematic itineraries aiming at the gradual improvement of the final products and services and hence the acquisition of the desired distinctiveness (see Figure 2).

Figure 2. Implementation framework of methodological approach

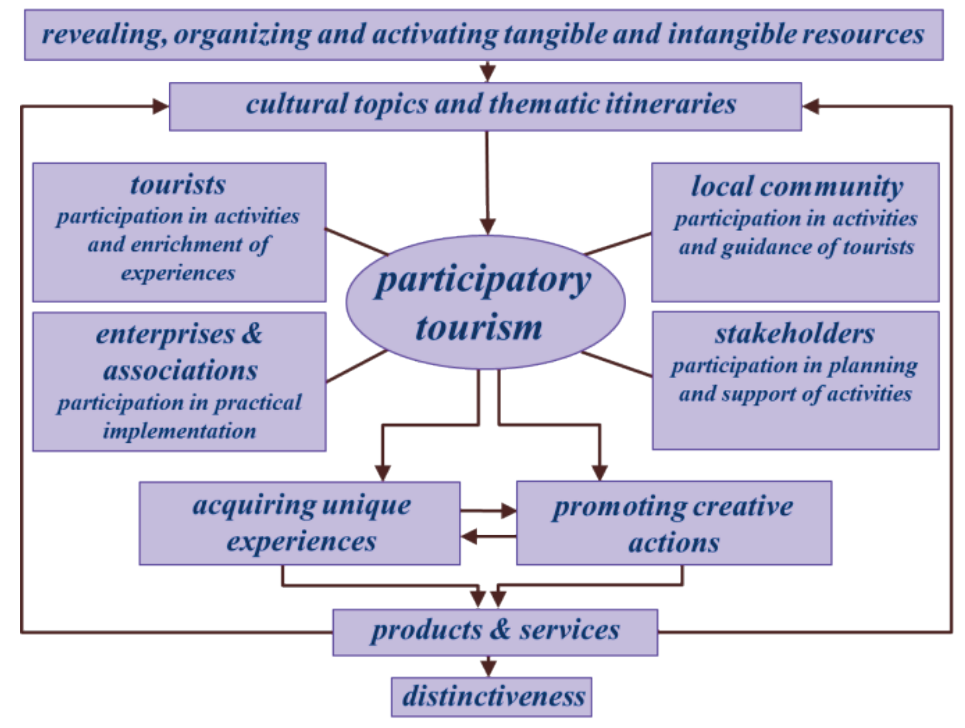

Source: Own illustration

\section{Evaluation and activation of Thessaly's local resources}

Having as criteria the importance, the condition and the spatial connection and integration of Thessaly's resources, we can initially create a list of the available resources. Trying to register these local resources a summary table of Thessaly's tangible and intangible resources was created according to values that characterized them as well as their territorial connection in the context of participatory and cultural tourism. This table can be used as a guiding tool for the production of final goods and services through the participatory tourism process or in the context of any rational development policy in the field of tourism.

Taking into consideration some indicative combinations ${ }^{4}$ of thematic tourist activities combined with the necessary existing tourism infrastructure, 20 thematic categories of potential itineraries emerged which can give at least 40 thematic itineraries of participatory and cultural tourism, respectively. Trying to map out these 40 thematic itineraries we realize the potential tourism activity in the whole region of Thessaly and the activation of alternative tourism forms, which can contribute at the same time through the participatory process to the creation of the appropriate goods and services that will lead to the qualitative restructuring of the tourism product and the distinctiveness of the place. By making a simple calculation we come to conclusion that, if in the case of Thessaly, the 20 thematic categories give 40 thematic itineraries of participatory and cultural tourism for about 45 weeks a year, 1,815 weekly thematic itineraries can be created per year. By estimating groups of at least 10 people we have approximately 20,000 tourists who if presumably spend at least 2,000 € each, including their stay, they will boost the region's economy by roughly $€ 40,000,000$ annually enhancing at the same time the local employment and regional development.

4 Taking into account 4 key thematic topics: tourism areas and tourism sites, archaeological sites and natural environment, local production and competitive advantages, cultural heritage - myths - sports and other activities. 


\section{Central management coordination}

In the context of the territorial approach of development, where distinctiveness serves as the base for competitiveness and attractiveness, the identification and activation of local specific tangible and intangible resources is the basis of a rational development procedure. The functionality of this procedure presupposes a central management coordination, control and feedback, appropriate and flexible supporting infrastructures and initiatives, as well as the planning of innovative participatory and cultural tourist activities through applicable thematic itineraries. The responsibilities of this body will aim at eliminating organizational rigidities in the public sector which exist mainly due to legislative constraints, protecting at the same time the social values, the natural and cultural heritage of the place. This body will also link the productive activities to the thematic itineraries that will emerge by coordinating in general and by feeding back the overall system. It will be responsible for the smooth and flexible flow of visitors, as well as for the utilization of human resources and experts, contributing decisively to strengthening local employment. Finally, it will be responsible for securing the coverage of operating costs and revenue management, let alone the dissemination and promotion of new tourism product. With the help of technology, the involvement of local communities, local authorities, research institutions and stakeholders, a network of local goods and services is emerging and is being activated by improving and supporting the efforts of mainly small enterprises to join the tourism market so as to effectively contribute to the tourism product restructure.

\section{CONCLUSION}

It is a fact that, whenever it is attempted to study the tourism activity, data and numbers are being analyzed that mainly refer to tickets, bookings, receipts and passengers. It must now be understood that we refer to citizens with desires and needs, aspirations and pictures, fears and insecurities, hopes and dreams, experiences and quests. These characteristics determine travel behaviors and have a decisive effect on the new trends in tourism. In order to guarantee and improve position of a country in the international tourism competition we must not rest on a relatively good picture of the overall number of tourist arrivals at the country's borders. A number of competitive, traditional and emerging tourist destinations is already claiming more shares from the international tourism market. It is necessary to redefine the tourism product on the international market by upgrading, diversifying and enriching the tourism supply with specific goals per market (Chatzidakis, 2015). Each tourist destination is required to increase its tourism attractiveness based on the use of its potential specific resources without relying on a political instability that may occur in a neighboring and touristically competitive country.

The thematic categories of potential participatory and cultural tourism itineraries developed above are the result of the territorial approach to development and the promotion of the specific tangible and intangible resources of the place. Aiming at a more balanced distribution of the tourism activity both in space and time we are being led to a gradual and smooth shift from uncontrolled mass arrivals to a controlled, qualitative and adapted approach to the visitors' interests, without adversely affecting the attractiveness of traditional local tourist destinations. Besides, by discovering and incorporating uniqueness that does not rely on the existence of the traditional and limited tourism product, but can constitute separate thematic units in the context of participatory and cultural tourism, we fully offset the economic benefits of the seasonal and cheap mass tourism growth (quantity), with the systematic and gradual spread of the activities offered by the new specialized tourism product (quality).With the guidance of a central body, responsible for managing and organizing activities based on distinctiveness and local values, everyone will benefit and the place will acquire a single dynamic identity and recognition, with a stable value in the highly competitive environment of the international tourism market. At the same time, the unique natural and cultural heritage will be protected from the continuous pressure of mass tourism concentration, strengthening also the local employment in all sectors of the economy. 


\section{REFERENCES}

Chatzidakis, A. (2015). Trends in the tourism activity 2008 - 2015. Greek National Tourism Organization, Athens, Greece.

De Bruin, A., \& Jelincic, D.A. (2016). Toward extending creative tourism: participatory experience tourism. Tourism Review, 71(1), 57-66.

Deffner, A. (2006). Tourism and Leisure Planning. Course Lectures. University of Thessaly, Department of Planning and Regional Development, Volos, Greece.

Goussios, D. (2016). Territorial approach and planning of rural areas. Course notes. Greek-French Master Program: Spatial Dynamics and Rural Planning (DYNTAR). University of Thessaly, Department of Planning and Regional Development, Volos, Greece.

Kostakis, M. (2003). Tourism - Culture. Worldwide experience. Conference presentation: Cultural Tourism and Development. National Centre for Public Administration and Local Government, Athens, Greece.

Pine II, J. B., \& Gilmore, J. H. (1998). Welcome to the experience economy. Harvard Business Review, 76(4), 97-105.

Richards, G. (2011). Creativity and Tourism: The State of the Art. Annals of Tourism Research, 38(4), 1225-1253.

Richards, G. \& Raymond, C. (2000). Creative Tourism. ATLAS News No. 23, pp. 16-20. ISSN 1388-3607.

UNWTO (2017). UNWTO Tourism highlights 2017 edition. Madrid: World Tourism Organization. 